\title{
Self-Assessment Video: An Effective Supplementary Learning \\ Tool in the Development of
Tardiovascular Examination Skills \\ Tool in the Development of
Cardiovascular Examination Skills of Medical Students
}

\author{
Melvin Remulla Marcial, MD, MHPEd
}

\section{ABSTRACT}

Background: Self-evaluation can augment the facilitation of acquiring knowledge, skills and attitude through a reflective method. Self-assessment video (SAV) can be a very useful reflective method tool that is student-centered and self-directed.

Objective: This study aimed to identify if SAV is an effective supplementary learning tool in improving cardiovascular examination knowledge, skills and attitude of second year medical students.

Methodology: A quasi-experimental two-group design with pre- and post-test was used. The study population by convenience sampling involved second year medical students of the University of Santo Tomas Faculty of Medicine and Surgery. A structured direct observation checklist on cardiovascular precordial examination was used, done on two occasions in a week interval period. The said examinations were recorded in a video and evaluated and scored by two independent facilitators on these two occasions. The experimental group had the opportunity to review their videos immediately after the two examinations and accomplished self-assessment form. One-Way Repeated Measures Multivariate Analysis of Variance (One-Way RM-MANOVA), a

Melvin Marcial

mp_marcial@yahoo.com

Associate Professor, Department of Medicine, Faculty of Medicine and Surgery, University of Santo Tomas, Manila, Philippines parametric multivariate test for between- and withingroup comparison of multiple dependent variables was used.

Results: It showed that there was a significant improvement in all parameters measured after the intervention (SAV in the experimental group compared to the control group).

Conclusion: The study showed that SAV is an effective supplementary learning tool in cardiovascular examination attitude, knowledge, and skills, and can be a very useful teaching and learning self-evaluation tool.

Key words: Self-Assessment Video, Reflective Learning, Self-Directed Learning, Learning Tools, Evaluation Tools.

\section{INTRODUCTION}

The second year level of being a medical student in the University of Santo Tomas, Faculty of Medicine and Surgery is crucial since this is the period they are introduced to the clinics. This is the stage wherein they will have actual patient encounters by doing history taking and performing physical examination. They are expected to arrive at a certain clinical impression or initial diagnosis with possible differential diagnoses in mind. Thus, they must be competent and confident in performing the correct physical examination and apply the knowledge they have acquired. The attitude, knowledge and skills 
they will acquire during this time will have a great influence on their future clinical practice.

The manner in which these physical examination knowledge, skills and attitudes are taught employs lectures, video demonstration, use of simulated patients, bedside teaching demonstration and repeated actual patient exposures and examinations. Aside from written examinations, the acquired knowledge, skills and attitude are evaluated by a facilitator, a well experienced clinician, using a structured checklist that can be used for formative assessment. Also, students undergo Objective Structured Clinical Examination (OSCE) at least twice a semester which is included in their summative assessment. However, these periodic assessment tools are not an assurance that students have really acquired the necessary knowledge and skills. The facilitator is expected to provide an accurate feedback to the medical students not only basing it on the checklist but during their bedside teaching rounds. The assessment of knowledge, skills and attitude acquired by the medical students are all dependent on the evaluation of the facilitator. However, in the real classroom set up, an average of 12-15 students are assigned per facilitator. Naturally, encounter time for each student with the facilitator is compromised. Thus, the evaluation of medical students' knowledge, skills and attitude are dependent mostly on the facilitators and periodic examinations. Are there any self-assessment tools that facilitators can employ to supplement evaluation of students' knowledge, skills and attitude in performing physical examination on patients?

Self-evaluation through self-assessment video (SAV) as one of the possible measuring tools can augment the facilitation of acquiring knowledge, skills and attitude through a reflective method. It is definitely the aim of every facilitator that their students turn into lifelong learners and critical thinkers. In traditional assessment, the teacher is solely responsible for the entire assessment procedure. In contrast, self-assessment is a form of alternative evaluation procedure wherein students are more involved in their own learning. This is essential for self-directed learning, an important skill for physicians throughout the clinical practice. Extensive research has been conducted pertaining to the impact of self-evaluation and self-assessment in relation to learning. [1-9] Hammoud et al. in 2012 conducted a review of literature involving
67 articles on the effectiveness of video review of medical students encounter with patients with regard to their learning. The article stated that video review alone was not generally effective. However, when combined with the feedback from the facilitator, it created a greater impact on medical student learning compared to the traditional method alone. The result of this literature review reflects that SAV can be a significant supplementary tool of learning. [1] In the same manner, the accuracy of students' self-assessment of practical clinical skills (suturing technique) using the video feedback was studied by Hawkins et al. in 2012 involving graduating medical students. The study showed that video feedback indeed helped the students assess their own clinical skills more correctly by seeing themselves personally. The study is relevant since it rendered objectivity in self-evaluation.[2]

This study aimed to identify if SAV was an effective supplementary learning tool in improving cardiovascular examination knowledge, skills and attitude of second year medical students. This study specifically aimed at determining whether there was significant improvement in the pretest and posttest scores in the cardiovascular examination knowledge, skills and attitude of the control and experimental groups before and after the SAV using a standardized cardiovascular examination checklist, learning from their own mistakes and mistakes of others.

\section{METHODOLOGY}

\section{Study Design and Population}

This is a quasi-experimental two-group design with pre- and post-test since there was no randomization done. The study population by convenience sampling involved second year medical students of the University of Santo Tomas, Faculty of Medicine and Surgery. This population was chosen because it is the year level in Medicine wherein they are introduced to cardiovascular physical examination at the novice level. Their knowledge on cardiovascular examination is developing and based only on their readings, lectures, video demonstration, standardized patient demonstration and encounter with minimal actual patient encounter. Thus, the difference that can be appreciated if ever in the preand post-test scores with or without the SAV will not be affected by previous knowledge and experience except by factors mentioned above. 
A total of 26 respondents were included and equally assigned in the control and experimental groups. Power analysis showed that a sample size of 26 acquired a power of $100 \%$ and large effect size $\left(f^{2}\right)$ of 3.16 at a significance of $5.00 \%$. Since the power is greater than the minimum allowable power of $80 \%$, the acquired sample size can be considered sufficient.[3]

\section{Research Instrument}

A structured direct observation checklist on cardiovascular precordial examination based on the book Marcial's Comprehensive Guide to Physical Examination, the official textbook of the UST second year Medicine 1 physical diagnosis subject, was used.[4] This checklist has been in use by the UST Department of Medicine for the last 10 years in formative assessment and a major component of summative assessment of the physical examination knowledge, skills and attitude (where the structure of the observation checklist used during OSCE is profoundly based). Likewise, it has been evaluated by the Department Chair of Medicine and Medicine 1 (Physical Diagnosis) Subject Supervisor. The said checklist is comprised of 50 items divided into three main parts: 7 points for attitude, 35 points for precordial examination skills and 8 points for knowledge. The point system is assigned as follows: 1.0 point if done very well, 0.75 point if done correctly but with some hesitation, 0.5 if done incorrectly and 0 if not done. (See Appendix)

\section{Study Groups}

There will be two groups in the study, the control and experimental groups. Both groups will undergo a structured direct observation test using a checklist on cardiovascular precordial examination done on two occasions in a week interval period. Ten minutes will be allotted to finish the examination. The said examinations will be recorded in a video. These videos will be evaluated and scored by two independent facilitators on these two occasions using a cardiovascular checklist. The experimental group will have the opportunity to review their videos immediately after the two examinations and will accomplish a self-assessment form.

\section{Statistical Design}

All statistical analyses were conducted using STATA Statistical Software, Version 13 (College Station, TX: StataCorp LP), and a p-value of 0.05 was considered statistically significant. Descriptive statistics included mean and standard deviation to describe the average knowledge, skills and attitude scores of the control and experimental groups. In contrast, inferential statistics involves One-Way Repeated Measures Multivariate Analysis of Variance (OneWay RM-MANOVA), a parametric multivariate test for between- and within-group comparison of multiple dependent variables. According to Daniel and Cross (2013), multivariate statistical analyses such as One-Way RM-MANOVA should be used in researches involving multiple dependent variables to avoid inflating family-wise error and the chances of committing type I (false positive errors). In the current study, there were three dependent variables - knowledge, skills and attitude. In order to avoid three-fold increase in the study's error, One-Way RM-MANOVA is the best to compare between- and within-group differences.[3]

\section{RESULTS}

\section{A. Between-Group Comparisons of Pre-test Knowledge, Skills and Attitude Scores}

Table 1 illustrates the descriptive statistics and comparative analyses of the pretest knowledge, skills and attitude between the control and experimental group. Scrutinizing the mean scores, it can be seen that knowledge, skills and attitude scores of the control group were $4.92( \pm 1.80), 6.93( \pm 0.96)$ and $4.95( \pm 1.03)$, respectively. The experimental group, on the other hand, acquired a mean knowledge, skills and attitude scores of $5.92( \pm 1.83), 9.64( \pm 0.85)$ and $4.73( \pm 1.03)$, respectively. Comparative analysis shows that in terms of pretest knowledge and attitude scores, comparisons were not statistically different, with F-value of $1.83(p=0.1890)$ and 0.29 $(p=0.5926)$, respectively. However, the pretest mean skill scores was statistically higher in the experimental group ( $F=58.16, p=0.00001)$. 
Table 1. Between-Group Comparison of Pre-test Mean Knowledge, Skills and Attitude Scores of the Control and Experimental Groups Contact ( $N=26$ )

\begin{tabular}{|c|c|c|c|c|c|c|}
\hline & \multicolumn{2}{|c|}{$\begin{array}{l}\text { Control Group } \\
(n=13)\end{array}$} & \multicolumn{2}{|c|}{$\begin{array}{l}\text { Experimental Group } \\
(n=13)\end{array}$} & \multirow[t]{2}{*}{ F-value } & \multirow[t]{2}{*}{$\begin{array}{c}\text { p-value } \\
\text { (Two-tailed) }\end{array}$} \\
\hline & Mean & SD & Mean & SD & & \\
\hline Pre-test Knowledge & 4.92 & \pm 1.80 & 5.92 & \pm 1.97 & 1.83 & 0.1890 \\
\hline Pre-test Skills & 6.93 & \pm 0.96 & 9.64 & \pm 0.85 & $58.16^{\dagger}$ & 0.00001 \\
\hline Pre-test Attitude & 4.95 & \pm 1.03 & 4.73 & \pm 1.03 & 0.29 & 0.5926 \\
\hline
\end{tabular}

Multivariate Analysis: Pillai's $=0.76, F=23.18, p=0.0001$

"Significant at $\leq \mathbf{0 . 0 5}$ level

tSignificant at $\leq \mathbf{0 . 0 1}$ level

B. Within-Group Comparisons of Pre-test and Post-test Knowledge, Skills and Attitude Scores

As presented in Table 2, comparative analysis using the RM-MANOVA show that from pre-test to post-test, the mean knowledge, skills and attitude scores increased from $5.92( \pm 1.83), 9.64( \pm 0.85)$, and $4.73( \pm 1.03)$ to $8.00( \pm 0.00), 11.08( \pm 0.31)$ and $7.00( \pm 0.00)$. The computed p-values were $0.0025,0.00001$ and 0.00001 , respectively. These results denote that the comparison from pretest to post-test scores were statistically significant indicating that there was a significant increase in the mean knowledge, skills and attitude scores of the experimental group.

Comparative analysis using RM-MANOVA show that from pre-test to post-test, the mean knowledge, skills and attitude scores decreased from $4.92( \pm 1.80)$ to $4.53( \pm 1.20)$ in knowledge, and increased from $6.93( \pm 0.96)$ to $7.12( \pm 0.89)$ in skills while it decreased from $4.95( \pm 1.03)$ to
$4.75( \pm 0.83)$ in attitude. The computed p-values were $0.3160,0.4658$ and 0.2536 , respectively. The results denote that the comparison from pre-test to post-test scores were not statistically significant indicating that there was no significant change in the mean knowledge, skills and attitude scores of the control group.

\section{Between-Group Comparisons of Post-test Knowledge, Skills and Attitude Scores}

Table 3 illustrates the descriptive statistics and comparative analyses of the post-test knowledge, skills and attitude between the control and experimental group. Scrutinizing the mean scores, it can be seen that knowledge, skill and attitude scores of the control group were $4.53( \pm 1.20)$, $7.12( \pm 0.89)$ and $4.75( \pm 0.83)$, respectively. The experimental group, on the other hand, acquired mean knowledge, skills and attitude scores of

Table 2. Within-Group Comparison of Mean Knowledge, Skills and Attitude Scores in the Experimental Group and the Control Groups ( $N=26)$

\begin{tabular}{|c|c|c|c|c|c|c|}
\hline & \multicolumn{2}{|c|}{ Pre-test } & \multicolumn{2}{|c|}{ Post-Test } & \multirow[t]{2}{*}{ F-value } & \multirow{2}{*}{$\begin{array}{c}\text { p-value } \\
\text { (Two-tailed) }\end{array}$} \\
\hline & Mean & SD & Mean & SD & & \\
\hline \multicolumn{7}{|c|}{ Experimental Group } \\
\hline Knowledge & 5.92 & \pm 1.97 & 8.00 & \pm 0.00 & $14.50^{\dagger}$ & 0.0025 \\
\hline Skills & 9.64 & \pm 0.85 & 11.08 & \pm 0.31 & $39.07^{\dagger}$ & 0.00001 \\
\hline Attitude & 4.73 & \pm 1.03 & 7.00 & \pm 0.00 & $63.34^{\dagger}$ & 0.00001 \\
\hline \multicolumn{7}{|l|}{ Control Group } \\
\hline Knowledge & 4.92 & \pm 1.80 & 4.53 & \pm 1.20 & 1.09 & 0.3160 \\
\hline Skills & 6.93 & \pm 0.96 & 7.12 & \pm 0.89 & 0.57 & 0.4658 \\
\hline Attitude & 4.95 & \pm 1.03 & 4.75 & \pm 0.83 & 1.44 & 0.2536 \\
\hline
\end{tabular}

Significant at $\leq 0.05$ level Significant at $\leq \mathbf{0 . 0 1}$ level 
Table 3. Between-Group Comparison of Post-test Mean Knowledge, Skills and Attitude Scores of the Control and Experimental Groups Contact $(\mathrm{N}=26)$

\begin{tabular}{|c|c|c|c|c|c|c|}
\hline & \multicolumn{2}{|c|}{$\begin{array}{l}\text { Control Group } \\
(n=13)\end{array}$} & \multicolumn{2}{|c|}{$\begin{array}{l}\text { Experimental Group } \\
(n=13)\end{array}$} & \multirow[t]{2}{*}{ F-value } & \multirow[t]{2}{*}{$\begin{array}{c}\text { p-value } \\
\text { (Two-tailed) }\end{array}$} \\
\hline & Mean & SD & Mean & SD & & \\
\hline Post-test Knowledge & 4.53 & \pm 1.20 & 8.00 & \pm 0.00 & $108.48^{\dagger}$ & 0.00001 \\
\hline Post-test Skills & 7.12 & \pm 0.89 & 11.08 & \pm 0.31 & $229.61^{\dagger}$ & 0.00001 \\
\hline Post-test Attitude & 4.75 & \pm 0.83 & 7.00 & \pm 0.00 & $95.73^{\dagger}$ & 0.00001 \\
\hline
\end{tabular}

Multivariate Analysis: Pillai's $=0.96, F=158.96, p=0.00001$

*Significant at $\leq \mathbf{0 . 0 5}$ level

tSignificant at $\leq \mathbf{0 . 0 1}$ level

$8.00( \pm 0.00), 11.08( \pm 0.31)$ and $7.00( \pm 0.00)$, respectively. Comparative analysis shows all three parameters were statistically different favoring the experimental group. Hence, we can conclude that the post-test mean knowledge, skills and attitude scores were statistically higher in the experimental group than the control group.

\section{Inter Rater Variability Between Evaluator 1 And Evaluator 2}

Table 4 illustrates the descriptive statistics and comparison of scores between evaluator 1 and evaluator 2 . Scrutinizing the comparative analyses, it shows that there was no significant difference between the mean scores acquired/observed by evaluator 1 and 2, with computed p-values of $0.3252,0.4128$ and 1.00 . These findings denote that there was no significant difference in the observations of evaluator 1 and evaluator 2 .

\section{E. Comparison of Pre-Test and Post-Test Scores Between Professor and Students}

Table 5 illustrates the descriptive statistics and comparative analyses of the knowledge, skills and attitude between the evaluation of students and professors. In terms of both pre-test and post-test knowledge scores, the evaluation scores were not statistically different between the professors and students ( $F=0.00, p=1.00$ ).

In terms of the pre-test skill scores, there was no significant difference in the evaluation scores $(F=0.09$, $p=0.7726$ ). However, the post-test skill scores was statistically different $(F=13.17, p=0.0013)$ wherein the post-test skill scores from professors had a mean score of $11.08( \pm 0.31)$ while the students had a selfevaluation score of $10.00( \pm 1.03)$, indicating under evaluation from the end of the students.

In terms of both pre-test and post-test attitude scores, the evaluative scores were statistically different: $F=13.01(p=0.0014)$ for the pre-test and $F=12.30 \quad(p=0.0018)$ for post-test. These results indicate that there is a significant difference in the mean pre-test and post-test attitude scores. Evaluating the mean pre-test score, it can be seen that the professors gave a score of $4.76( \pm 1.03)$ while students evaluated themselves with a mean score of $5.98( \pm 0.71)$, indicating overestimation of scores. However, at post-test, students significantly evaluated themselves lower $(M=6.52, S D=0.49)$

Table 4. Comparison of scores between evaluator 1 and evaluator 2

\begin{tabular}{|c|c|c|c|c|c|c|}
\hline & \multicolumn{2}{|c|}{$\begin{array}{c}\text { Evaluator } 1 \\
(n=13)\end{array}$} & \multicolumn{2}{|c|}{$\begin{array}{c}\text { Evaluator } 2 \\
(n=13)\end{array}$} & \multirow[t]{2}{*}{ F-value } & \multirow[t]{2}{*}{$\begin{array}{c}\text { p-value } \\
\text { (Two-tailed) }\end{array}$} \\
\hline & Mean & SD & Mean & SD & & \\
\hline Mean Attitude & 4.730769 & 1.028052 & 4.346154 & .9216067 & $1.01^{\dagger}$ & 0.3252 \\
\hline Mean Skills & 9.641538 & .8534621 & 9.353077 & .9104979 & 0.09 & 07726 \\
\hline Mean Knowledge & 5.923077 & 1.966873 & 5.923077 & 1.966873 & $0.00^{\dagger}$ & 1.0000 \\
\hline
\end{tabular}

Multivariate Analysis: Pillai's $=0.96, F=158.96, p=0.00001$ 
Table 5. Comparison of pre-test and post-test scores between Professor and Students

\begin{tabular}{|c|c|c|c|c|c|c|}
\hline \multirow[t]{2}{*}{ PRE-TEST } & \multicolumn{2}{|c|}{$\begin{array}{c}\text { Professor } \\
(n=13)\end{array}$} & \multicolumn{2}{|c|}{$\begin{array}{l}\text { Students } \\
(\mathrm{n}=13)\end{array}$} & \multirow[t]{2}{*}{ F-value } & \multirow[t]{2}{*}{$\begin{array}{c}\text { p-value } \\
\text { (Two-tailed) }\end{array}$} \\
\hline & Mean & SD & Mean & SD & & \\
\hline Mean Attitude & 4.730769 & 1.028052 & 5.980769 & .7104982 & 13.01 & 00014 \\
\hline Mean Skills & 9.641538 & .8534621 & 9.55 & .7397748 & 0.09 & 0.7726 \\
\hline Mean Knowledge & 5.923077 & 1.966873 & 5.923077 & 1.966873 & $0.00^{\dagger}$ & 1.0000 \\
\hline \multirow[t]{2}{*}{ POST-TEST } & \multicolumn{2}{|c|}{$\begin{array}{c}\text { Professor } \\
(n=13)\end{array}$} & \multicolumn{2}{|c|}{$\begin{array}{c}\text { Students } \\
(n=13)\end{array}$} & F-value & $\begin{array}{c}\text { P-value } \\
\text { (Two-tailed) }\end{array}$ \\
\hline & Mean & SD & Mean & SD & & \\
\hline Mean Attitude & 7 & 0 & 6.519231 & .4943592 & 12.30 & 0.0018 \\
\hline Mean Skills & 11.08231 & .3115861 & 10 & 1.029296 & 13.7 & 0.0013 \\
\hline Mean Knowledge & 8 & 0 & 8 & 0 & & \\
\hline
\end{tabular}

than the professor's evaluation $(M=7.00, S D=0.00)$ denoting underestimation of attitude scores.

In terms of pre-test and post-test knowledge scores, there was no significant difference in the evaluation scores $(F=0.00, p=1.0000)$.

\section{F. Within-Group Comparison of Self-Evaluation Mean Knowledge, Skills and Attitude Pre-Test And Post-Test Scores}

Table 6 illustrates the descriptive statistics and comparative analyses of the with-in group comparison of self evaluation mean knowledge, skills and attitude pre-test and post-test scores of the experimental group. In terms of both pre-test and post-test knowledge, skills and attitude scores, the evaluative scores were statistically different $F=14.5(p=0.0025), F=5.18 \quad(p=0.0420), F=14.0$ $(p=0.0028)$ respectively, indicating improvement in their self evaluation scores after the intervention.

\section{DISCUSSION}

Assessment strategies undoubtedly are an important aspect in medical education in which the most important goal is to improve student learning by converting declarative knowledge into functioning knowledge. In order to achieve this goal, there is a need for a flawless relationship among the teaching, learning and assessment methods through which students are empowered to take increased responsibility for their learning. Self-assessment as a form of reflective assessment has an important role in this aspect.[5] Reflective assessment or metacognition is nurtured from strong theoretical roots of the constructivist theories of John Dewey, Jean Piaget and Plato.[6] It is a concept of cognitive psychology which focuses on active participation of the individual in his or her thinking process.[7] It involves thinking and emphasizes the individual's self-awareness of his or her thinking patterns,

Table 6. Within-Group Comparison of Self-Evaluation Mean Knowledge, Skills and Attitude Pre-Test And Post-Test Scores $(\mathrm{N}=13)$

\begin{tabular}{lcccccc}
\hline & \multicolumn{2}{c}{ Pre-test } & \multicolumn{2}{c}{ Post-Test } & F-value & $\begin{array}{c}\text { P-value } \\
\text { (Two-tailed) }\end{array}$ \\
\cline { 2 - 5 } & Mean & SD & Mean & SD & & 0.0025 \\
\hline Knowledge & 5.92 & \pm 1.97 & 8.00 & \pm 0.00 & $14.50^{\dagger}$ & 0.0420 \\
Skills & 9.55 & \pm 0.74 & 10.00 & \pm 1.03 & $5.18^{*}$ & 0.0028 \\
Attitude & 5.98 & \pm 0.71 & 6.52 & \pm 0.49 & $14.00^{\dagger}$ & \\
\hline
\end{tabular}


learning characteristics and techniques which aid both memory and comprehension. [8]

Accurate self-assessment of performance allows future physicians to understand their own strengths and weaknesses and know which areas to focus on in their medical education. Self-assessment is considered as a component of establishing clinical competence in medical school. The value of videobased self-assessment of communication skill involving 674 first year medical students were documented by the study of Zick et al. in 2007. It was shown to be very informative, feasible and practical in terms of self-assessment providing students great help in developing their communication skills with simulated patients. Introducing SAV early on first year medical students can provide a good avenue for improving their skills in the early part of training.[9]

Results in this study showed improvement in scores in all aspects of learning such as knowledge, skills and attitude in the cardiovascular examination, after having the opportunity to evaluate oneself with SAV. Giving the opportunity for medical students to participate in assessing one's own strength and weaknesses with regards to what they know, feel and do will definitely help them realize the challenges that they must address early in their medical career.

The act of self-assessment is an intrinsically difficult task that prevents people from reaching truthful selfimpressions. In their systematic review, Davis D. et al. found the worst accuracy in self-assessment among physicians who displayed the least skill and also those who were the most confident. These results suggest that those who are overconfident and lacking in skill tend to ignore self-evaluation and self-assessment placing their patients in danger.[10] Students tend to be overconfident in newly learned skills. In order to maximize learning and performance, students need to be educated in the area of self-evaluation and self-assessment. Consideration must be given to the idea of repairing self-assessments that may be flawed rather than just ignoring them.[11] People tend to have overestimated views of their abilities. Overestimation may be due to the fact that the poorly skilled not only reach erroneous conclusions and make unfortunate choices, but their incompetence makes them unable to realize it.[12]

In 2016, Herrera-Almario conducted a study of video review of laparoscopic surgical skills involving surgical residents. The residents gave themselves a lower score compared to their consultants. The result does not really differ from other studies wherein the examinees were more critical of themselves once they were given a chance to see their video compared to the evaluation of their consultant. This attitude may render advantage to the student by setting a higher standard for himself reiterating its important role in self-directed learning.[13] However, Davis in 2006 observed that students over-evaluated themselves. [10] In our study, this was compatible in the pretest self-evaluation. On the contrary, post-test results showed self-evaluation to be lower which may be due to the fact that they became very critical of what they have seen in the SAV. After which, they tend to be very meticulous in evaluating themselves, realizing the fact that they will benefit in all aspects of learning if they will be truthful to themselves with regard to the area that they must strive for to master.

Self-assessment learning methods can also be an instrument for peer assessment with the principle of being able to evaluate and recognize the strength and weaknesses of their classmates. Likewise, it promotes group dynamics, critical thinking skills and learning from the mistakes of others without committing the same mistakes. However, in the study of Ryan, et al. in 2007, students did not like peer assessment using forced distribution of grades. [14]

It is interesting to note that the study of Eekhout, et al. in 2016 about the use of video training in real-time consultation among physicians in the general practice setting with peer feedback resulted in a positive impact ( $>90 \%$ of the study population) with regards to their own communication skills by observation and evaluation of oneself and peers. [15] The researcher as well as participants recognized the underutilization of the power of video in improving communication and other performance-based skills. This study reiterated the possible usefulness of this learning tool in the field of medical education and most likely in other fields of education as well. Other practical implications include the reduced burden for the facilitators in terms of time investment by utilizing peer tutoring and self-directed learning.

Hulsman, et al. in 2009 conducted a study involving this time second year medical students recording their consultation with simulated patients. Aside from reviewing their own videos, a peer evaluation was likewise done. The result showed that such an activity was instructive and reflective. 
This study supports the concept that SAV can be a very useful tool in reflective learning. Likewise, such can be an avenue for a possible 360-degree way of learning wherein peers can help evaluate their classmate via constructive criticisms and at the same time compare their strengths and weaknesses to that of their classmates.[16] Again Hulsman in 2015, with the same concept of self and peer evaluation, used a web-based video annotation system as an innovative tool in evaluating its usefulness in reflective learning. The study showed that there were more negative annotations when self-evaluation was done but more positive annotations were given when assessing peers. The results of these studies imply that medical students were more critical about themselves being compared when evaluating their peers. This may create a positive impact on the behavior of medical students towards recognizing areas where they need improvement and therefore can remediate them early on in the course of their medical training.[17] Thus, self-assessment is more of a learner-centered evaluation tool compared to the traditional teacher-centered form of assessment. [17]

On the part of the facilitator, such self-evaluation tools will complement their evaluation of the student's performance objectively. With this evaluation tool, they can give feedbacks that can be of use for students. A study conducted in 2016 among medical students of the University of Geneva in Switzerland compared the advantage of video-based feedback versus direct or verbal feedback by the clinical supervisors. It showed that video-based feedback was more engaging for the students and facilitated discussion with regards to clinical reasoning, attitude communication and clinical skills as well. Clearly, this study showed the advantage of the video-based format over the more traditional direct or verbal feedback. The video-based feedback format can help both the facilitator and medical students in achieving their targeted educational goal in a manner that is more engaging for the medical students. [18] ln 2015, a pilot study involving graduating medical students of the University of Heidelberg Medical Hospital was conducted using a video-based feedback. The medical students performed supervised medical routine procedures at the bedside (history taking, physical examination and cannulation) while being filmed. After which, an oral feedback loop was made comprising of the patient, supervisor and the students themselves. The supervisor feedback was noted to be highly beneficial with the video itself regarded as an important tool in determining crucial feedback. The procedure was well accepted by both the students and patients and regarded as realistic. The constructive criticisms made by the patients were helpful as well. With this study, this form of feedback mechanism can be viewed as an additional learning tool combined with the feedback coming from the supervisor and patient. This feedback format can be done routinely and combined with other feedback formats in the field of medical education. [19]

Studies stated above show that SAV can really be a supplemental learning tool in all stages of medical training, from undergraduate to postgraduate residency training. Self-assessment methods would need the support and feedback of the teacher/ facilitator in order for such a reflective method of learning to be productive for the student. However, since it may entail additional time and effort to be a successful assessment tool, some resistance in its implementation may be encountered. In order to increase its fidelity of implementation, the importance of this kind of reflective learning, especially in the field of medical education must be emphasized. Adequate faculty preparation and orientation must be carried out on a regular basis to avoid a flawed system on implementing this self-assessment learning method.[11] Indeed, self-directed learning has been shown to be effective in improving the skills expected from medical trainees. Competence is lifelong learning and self-assessment is integral in identifying learning requirements.

\section{CONCLUSION}

This study on SAV shows that it is an effective supplementary learning tool in the cardiovascular examination knowledge, skills and attitude of second year medical students. It showed that there was a significant improvement in all parameters measured after the intervention (SAV) and can be a very useful teaching and learning self-evaluation tool. It is studentcentered and a self-directed learning instrument. This paper presented a model of reflective practice and materials for teaching the learning tool in the practice of medicine. It would address the challenge of helping students understand what reflection is, 
how to do it to achieve deeper learning and its value and benefits.

\section{RECOMMENDATIONS}

It is recommended that SAV be used as a supplementary learning tool in medical schools and schools with allied health sciences as a form of reflective learning with a goal of higher learner achievement.

The SAV can be used not only in cardiovascular examination but in all aspects of teaching and learning physical examination skills, applying core knowledge and attitude formation.

A higher number of study populations or ideally the entire universe in UST medical school and other medical schools would be included in order to really assess the impact of the said learning tool.

It can be used also in the postgraduate level of training in medicine (whatever specialty or subspecialty) wherein a higher level of competency is expected. The facilitators must be able to confront students' feelings and beliefs of self-evaluation by open communication. Asking a reflection from the students (oral or written) after the self-evaluation process, its impact on them in terms of learning (skills, knowledge and attitude) would be ideal.

Likewise, the facilitators must be able to make the benefits of self-evaluation visible to students by regular feedbacks, personally telling and showing them their strengths and weaknesses for remediation.

The SAV can also be used as a teaching and learning tool for peer assessment wherein one can learn from each other's strengths and weaknesses and be able to address and share certain concerns commonly experienced by them with the guidance of the facilitator.

Disclosure and Conflict of Interest

No potential conflict of interest was reported by the author.

\section{Acknowledgment}

Prof. Marcela Leus, D Ed, UST Graduate School

Marie Stella Navarro, MD, USTFMS, Department of Medicine 


\section{REFERENCES}

1. Hammoud M, Morgan, Edwards, Lyon, White. Is video review of patient encounters an effective tool for medical student learning? A review of the literature. AMEP [Internet]. 2012 Mar;19. Available from: http://dx.doi. org/10.2147/AMEP.S20219

2. Hawkins SC, Osborne A, Schofield SJ, Pournaras DJ, Chester JF. Improving the accuracy of self-assessment of practical clinical skills using video feedback - The importance of including benchmarks. Medical Teacher [Internet]. 2012 Mar 28;34(4):279-84. Available from: http://dx.doi.org/ 10.3109/0142159X.2012.658897

3. Daniel WW, Cross CL. Biostatistics: a foundation for analysis in the health sciences (10th ed.). U.S.A. Wiley Inc.; 2013.

4. Marcial MR. Comprehensive guide to physical examination. Manila UST Publishing House; 2015.

5. Epstein RM. Defining and assessing professional competence. JAMA [Internet]. 2002 Jan 9;287(2):226. Available from: http://dx.doi.org/10.1001/jama.287.2.226

6. Bond JB. Reflective assessment: including students in the assessment process. In: Forum on Public Policy Online 2007 (Vol. 2007, No. 3, p. n3). Oxford Round Table. 406 West Florida Avenue, Urbana, IL 61801. Retrieved from http://www.forumonpublicpolicy.com/ archivesum07/bond.pdf

7. Stewart J, Landine J. Study skills from a metacognitive perspective. Guidance \& Counseling 1995;11(1):16-20.

8. Schneider W, Borkowski JG, Kurtz BE, Kerwin K. Metamemory and motivation. Journal of Cross-Cultural Psychology [Internet]. 1986 Sep;17(3):315-36. Available from: http://dx.doi.org/10.1177/0022002186017003005

9. Zick A, Granieri M, Makoul G. First-year medical students' assessment of their own communication skills: A videobased, open-ended approach. Patient Education and Counseling [Internet]. 2007 Oct;68(2): 161-6. Available from: http://dx.doi.org/10.1016/i.pec.2007.05.018

10. Davis DA, Mazmanian PE, Fordis M, Van Harrison R, Thorpe KE, Perrier L. Accuracy of physician self-assessment compared with observed measures of competence. JAMA [Internet]. 2006 Sep 6;296(9):1094. Available from: http://dx.doi.org/10.1001/jama.296.9.1094

11. Pisklakov S. Role of self-evaluation and self-assessment in medical student and resident education. BJESBS [Internet]. 2014 Jan 10;4(1):1-9. Available from: http://dx.doi. org/10.9734/BJESBS/2014/5066

12. Kruger J, Dunning D. Unskilled and unaware of it: How difficulties in recognizing one's own incompetence lead to inflated self-assessments. Journal of Personality and Social Psychology [Internet]. 1999;77(6):1121-34. Available from: http://dx.doi.org/10.1037/0022-3514.77.6.1121

13. Herrera-Almario GE, Kirk K, Guerrero VT, Jeong K, Kim S, Hamad GG. The effect of video review of resident laparoscopic surgical skills measured by self- and external assessment. The American Journal of Surgery [Internet]. 2016 Feb;21 1 (2):315-20. Available from: http://dx.doi. org/10.1016/i.amjsurg.2015.05.039

14. Ryan G, Marshall L, Porter KB, Jia H. Peer, professor and self-evaluation of class participation. Active Learning in Higher Education. 2007;8:49-61.
15. Eeckhout T, Gerits M, Bouquillon D, Schoenmakers B. Video training with peer feedback in real-time consultation: acceptability and feasibility in a general-practice setting. Postgrad Med J [Internet]. 2016 Feb 3;92(1090):4315. Available from: http://dx.doi.org/10.1136/ postgradmedj-2015-133633

16. Hulsman RL, Harmsen AB, Fabriek M. Reflective teaching of medical communication skills with DiViDU: Assessing the level of student reflection on recorded consultations with simulated patients. Patient Education and Counseling [Internet]. 2009 Feb;74(2): 142-9. Available from: http:// dx.doi.org/10.1016/i.pec.2008.10.009

17. Hulsman RL, van der Vloodt J. Self-evaluation and peerfeedback of medical students' communication skills using a web-based video annotation system. Exploring content and specificity. Patient Education and Counseling [Internet]. 2015 Mar;98(3):356-63. Available from: http://dx.doi. org/10.1016/i.pec.2014.11.007

18. Perron NJ, Louis-Simonet M, Cerutti B, Pfarrwaller E, Sommer J, Nendaz M. Feedback in formative OSCEs: comparison between direct observation and video-based formats. Medical Education Online [Internet]. 2016 Jan 1;21(1):32160. Available from: http://dx.doi.org/10.3402/meo. v21.32160

19. Groener J, Bugaj T, Scarpone R, Koechel A, Stiepak J, Branchereau $S$, et al. Video-based on-ward supervision for final year medical students. BMC Med Educ [Internet]. 2015 Dec;15(1). Available from: http://dx.doi.org/10.1186/ s1 2909-015-0430-2

\section{(i)}

Open Access This article is licensed under a Creative Commons Attribution 4.0 International License, which permits use, sharing, adaptation, distribution and reproduction in any medium or format, as long as you give appropriate credit to the original author(s) and the source, provide a link to the Creative Commons license, and indicate if changes were made. The images or other third party material in this article are included in the article's Creative Commons license, unless indicated otherwise in a credit line to the material. If material is not included in the article's Creative Commons license and your intended use is not permitted by statutory regulation or exceeds the permitted use, you will need to obtain permission directly from the copyright holder. To view a copy of this license, visit http://creativecommons.org/licenses/by/4.0/.

\section{APPENDICES}

\section{INFORMED CONSENT}

\section{TITLE OF STUDY}

Self-Assessment Video as an Effective Supplementary Learning Tool in Improving the Cardiovascular Examination Knowledge, Attitude and Skills of Second Year Medical Students in University of Santo Tomas Faculty of Medicine and Surgery 
INVESTIGATOR

Melvin R. Marcial, MD

\section{PURPOSE OF STUDY}

You are being asked to take part in a research study. Before you decide to participate in this study, it is important that you understand why the research is being done and what it will involve. Please read the following information carefully. Please ask the researcher if there is anything that is not clear or if you need more information.

As a physician later on who will be dealing always with life, ideally, there must be no room for error. It is definitely the aim of every facilitator that their students turn into a lifelong learners and critical thinkers. And in order for that to happen, an effective learning tool is needed. Self-assessment video has a very high potential of augmenting facilitation of acquiring knowledge and skills through reflective method.

\section{STUDY PROCEDURES}

There will be 2 groups in the study. Both groups will undergo a structured direct observation test using a checklist on cardiovascular precordial examination done on two occasions in a week interval period. Ten minutes will be allotted to finish the examination. The said examinations will be recorded in a video. These videos will be evaluated and scored by 2 independent facilitators on these 2 occasions using a cardiovascular checklist. One group will have the opportunity to review their videos immediately after the two examinations and will accomplish a selfassessment form.

\section{BENEFIT}

There will be no direct benefit to you for your participation in this study but you will have the opportunity to reflect on your knowledge, skill and attitude as you review your video (for the experimental group). For the control group, this activity will provide additional opportunity to practice cardiovascular examination. However, we hope that the information obtained from this study may help the succeeding students to gain competence in this area of physical examination.

\section{CONFIDENTIALITY}

Participant data will be kept confidential except in cases where the researcher is legally obligated to report specific incidents. These incidents include, but may not be limited to, incidents of abuse and suicide risk.

\section{CONSENT}

I have read and I understand the provided information and have had the opportunity to ask questions. I understand that my participation is voluntary and that I am free to withdraw at any time, without giving a reason and without cost. I understand that I will be given a copy of this consent form. I voluntarily agree to take part in this study.

Participant's signature

Date

Investigator's signature

Date

\title{
UNIVERSITY OF SANTO TOMAS
}

\author{
Faculty of Medicine \& Surgery
}

Cardiovascular Examination

Name

\section{Evaluator 123}

Test No. 1
GRP A B

Time Started

Date
Time Finished 


\begin{tabular}{l|l|l|l}
\hline General rules & $\begin{array}{c}\text { Done very } \\
\text { Well }\end{array}$ & $\begin{array}{c}\text { Done } \\
\text { properly } \\
\text { done }\end{array}$ & $\begin{array}{c}\text { Not done } \\
0.5\end{array}$ \\
\hline At the beginning of every procedure & 1.0 & .75 & \\
\hline 1. Explain procedure & & & \\
\hline 2. Ask permission & & & \\
\hline 3. Get consent & & & \\
\hline 4. Prepare equipment/supplies & & & \\
\hline 5. Ensure patient's comfort & & & \\
\hline At the end & & & \\
\hline 6. Say thank you & & & \\
\hline Sequence of examination & & & \\
\hline 7. Precordium (Inspection, Palpation, Auscultation order of sequence) & & & \\
\hline SUBTOTAL 7 pts & & & \\
\hline
\end{tabular}

\section{PRECORDIAL INSPECTION}

8. Stand or sit at the right side of the patient.

9. Position the patient supine at 45-degree angle.

10. Expose patient's chest area and drape so as not to compromise patient's privacy.

11. Illuminate the precordium from a single source, (penlight) shining transversely or tangentially across the patient's anterior chest surface.

12. Check for precordial bulging and visible pulsations on the precordium at eye level.

13. Look for the apex beat.

If no visible lateral pulsation is noted, concentrate on its usual location in the $5^{\text {th }}$ or $6^{\text {th }}$ intercostal space $1-2 \mathrm{~cm}$ medial from the midclavicular line or up to $7-9 \mathrm{~cm}$ from the midsternal line or laterally to the same intercostal space anterior, mid or posterior axillary line.

If visible from inspection, palpate for the apical impulse using the tip of the right middle and index fingers

14. From the angle of Lovis, slide fingers laterally to the left parasternal intercostal spaces and count what intercostal space the apex beat is located.

15. Using a graduated ruler $(\mathrm{cm})$ note how far away from the left midclavicular line or from the mid sternal line is the apex beat is found.

16. Report findings of apex beat location

17. Without taking the fingers off the possible apical impulse, assess the impulse size by asking the patient to lie in left lateral decubitus.

18. Report findings. Compare the size, amplitude, contour, duration and timing of the apical impulse in this position versus its characteristics on supine.

19. Return patient in supine position at 45-degree angle.

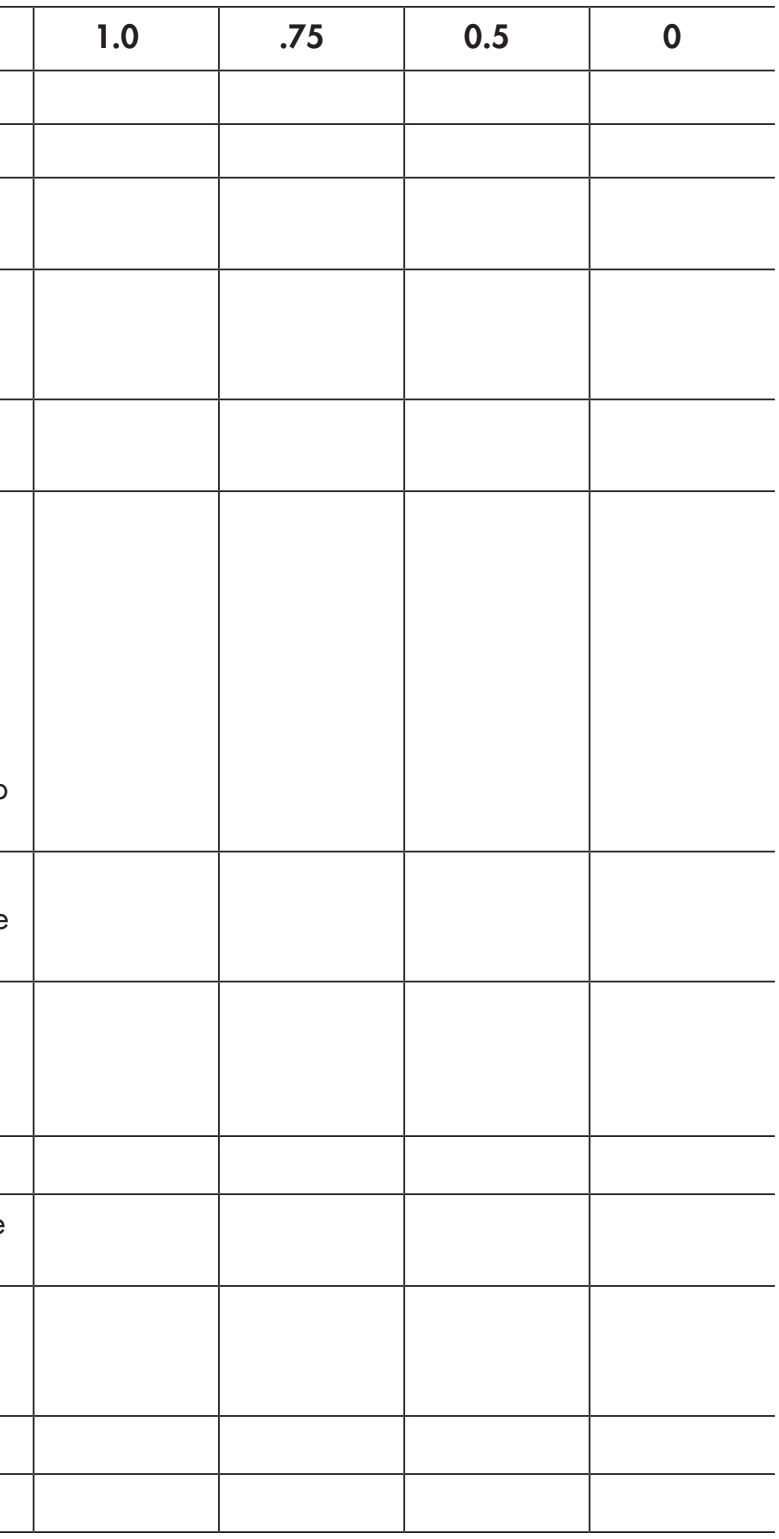


PRECORDIAL PALPATION: HEAVES

西

(2)

20. Using the heel of right hand, palpate for abnormally strong pulsations (left ventricular heave) over the area of the apex beat.

21. Using the heel of right hand, palpate for abnormally strong pulsation (right ventricular heave) over the left side of the lower sternum.

\section{PRECORDIAL PALPATION: THRILLS}

22. Using the ball of hand, feel for fine vibratory sensations over the following areas:

23. apex beat of the $5^{\text {th }} I C S, L M C L$ for mitral valve thrill

24. left lower sternum for tricuspid valve thrill

25. $2^{\text {nd }}$ ICS LPSL for pulmonic valve thrill

26. $2^{\text {nd }}$ ICS RPSL for aortic valve thrill

\section{PRECORDIAL PALPATION: LIFTS}

27. Using the pad of the right middle and index fingers, palpate for abnormal pulsation over the $2^{\text {nd }}$ ICS LPSL for pulmonary artery lift.

28. Using the pad of the right middle and index fingers, palpate for abnormal pulsation over the $2^{\text {nd }}$ ICS RPSL for aortic artery dilatation.

29. Using the pad of the right middle and index fingers, palpate for abnormal pulsation over the $3^{\text {rd }}$ and $4^{\text {th }}$ ICS LPSL for left atrial lift.

30. Reporting of precordial palpation findings

\section{SUBTOTAL 10 pts}

\section{PRECORDIAL AUSCULTATION}

31. Warm the stethoscope using the hands or clothing.

32. Using the bell or diaphragm of the stethoscope, auscultate at the different auscultatory valvular areas in an inching manner (either from apex to base or base to apex)

33. mitral valve at the $5^{\text {th }} \mathrm{ICS} L M C L$

34. tricuspid valve at the left lower prosternum

35. pulmonic valve at the $2^{\text {nd }}$ ICS LPSL

36. aortic valve at the $2^{\text {nd }} I C S$ RPSL

37. Erb'spoint at the $3^{\text {rd }}$ and $4^{\text {th }}$ ICS LPSL

\section{Describe the character of heart sounds in the following} areas:

38. S1 (apex) loud

39. S2 (apex) soft

40. S1 (base) soft

41. S2 (base) loud w/ or w/o split

\section{PRECORDIAL AUSCULTATION: MANEUVERS}

42. Patient to assume a left lateral decubitus position to accentuate heart sounds in the tricuspid and mitral areas (apical).

43. Patient to lean forward to accentuate heart sounds in the pulmonic and aortic areas (base).

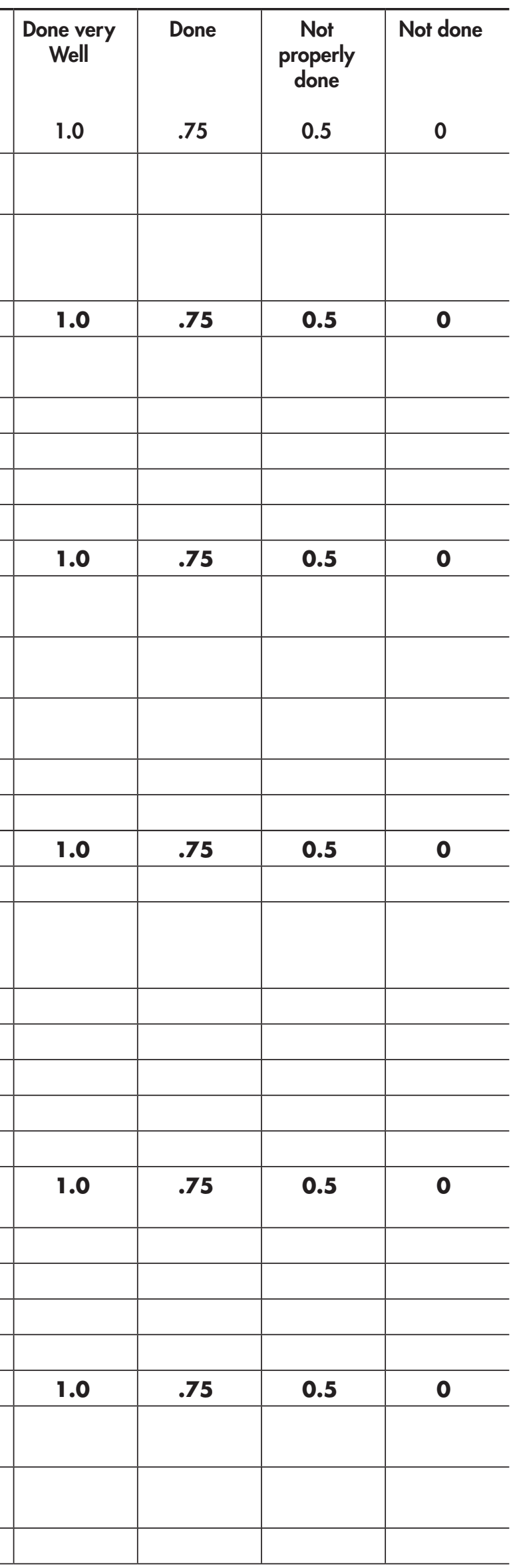




\begin{tabular}{|c|c|c|c|}
\hline ANSWER THE FOLLOWING QUESTIONS: & Answer & $\begin{array}{l}\text { Correct } \\
\text { Answer }\end{array}$ & $\begin{array}{l}\text { Incorrect } \\
\text { Answer }\end{array}$ \\
\hline \multicolumn{4}{|c|}{ What are the clinical implications of the following precordial findings? } \\
\hline \multicolumn{4}{|c|}{ 44. LV heave } \\
\hline \multicolumn{4}{|l|}{ 45. RV heave } \\
\hline \multicolumn{4}{|l|}{ 46. PA lift } \\
\hline \multicolumn{4}{|l|}{ 47. LA lift } \\
\hline \multicolumn{4}{|l|}{ 48. Thrill is associated with at least what grade of murmur? } \\
\hline \multicolumn{4}{|l|}{ 49. Location of apex beat with left ventricular hypertrophy } \\
\hline \multicolumn{4}{|l|}{ 50. Location of apex beat with right ventricular hypertrophy } \\
\hline \multicolumn{4}{|l|}{ 51. Clinical significance of S3 gallop } \\
\hline SUBTOTAL 8 pts & & & \\
\hline
\end{tabular}

SUMMARY OF SCORES

\begin{tabular}{l|c|c}
\hline & NO OF ITEMS & Correct Answer \\
\hline PART 1: ATTITUDE & 7 & \\
\hline PART 2: SKILLS: INSPECTION & 12 & \\
\hline PART 3: SKILLS: PALPATION & 10 & \\
\hline PART 4: SKILLS: AUSCULTATION & 13 & \\
\hline PART 5: KNOWLEDGE & 8 & \\
\hline GRANDTOTAL & 50 & \\
\hline
\end{tabular}

